\title{
A Study on Safety Audit Management System in Kuwait
}

\author{
Sophiya Sunny Pulickal ${ }^{1}$, Blessy B. ${ }^{2}$, Pratab Reddy ${ }^{3}$ \\ ${ }^{1}$ P.G Student, Department of Civil Engineering, RVS Technical Campus, Coimbatore, India \\ ${ }^{2}$ Assistant Professor, Department of Civil Engineering, RVS Technical Campus, Coimbatore, India \\ ${ }^{3}$ Safety Engineer, SSH International, Kuwait
}

\begin{abstract}
A construction site is one of the most risky, perilous and accident prone working environment. Everyday construction personnel are exposed to a lot of site perils that could result in injury or even fatality. A complete eradication of these construction site dangers are close to impossibility but, it can be reduced to a considerable extent. The safety audit management system is one step to achieve a better, safe and accident-free working environment. A safety audit was prepared on MS Excel and 19 major elements were selected for the study. The audit was implemented in SSH International, Kuwait. For the collection of data for the audit, physical checks/inspections were done. Safety engineers, safety officers and others involved in addressing the safety at the workplace were contacted. Safety records, safety logs, safety registers, minutes of safety meetings, etc. were assessed. The factors that could affect the health and safety of the workers at the site were then ranked based on their criticality. The audit score for the consultancy was $79 \%$. Out of the 19 audits elements, 6 elements were ranked as the primary and secondary causes of accidents. The improper usage of the following 6 elements could affect the Health and the safety of the construction personnel at the aforementioned construction site. The six elements were the following: Amenities/Sanitation, Electrical Works, Excavations, Tools and equipment, Fire protection and hot works, and Personal Protective Equipment's (PPE's). The practical implication of the audit is that the actual work-site conditions could be taken into account through the audit, and based on the happenings at the work-site, suggestive measures could be given.
\end{abstract}

Keywords: Audit; safety; construction

\section{Introduction}

An audit is a systematic and wherever possible, independent examination to determine whether activities and related results conform to planned arrangements and whether these arrangements are implemented effectively and are suitable to achieve the organizations policy and objectives. (BS 8800:1996 Guide to Occupational Health and Safety Management System)

A safety audit examines and determines whether or not a company's daily activities and processes conform to their planned health and safety arrangements as well as the government laws. An audit further identifies whether or not the planned arrangements are implemented effectively, and are suitable to achieve the organizations health and safety policy objectives. Often it is a failure in the health and safety management that results in serious incident. Safety audits assist in identifying failures within a system, process or program and the information gathered helps to determine the best course of corrective action.

Extensive studies have been done on safety audits over the past years. A comprehensive literature review showed that the Safety Audits could impact an organization in a tremendously positive way.

This paper aims at preparing a safety audit, conducting the audit in SSH International, Kuwait, finding out the root causes that could affect the health and safety of the construction personnel, suggesting improvement measures to make the work place a better safe place to the construction personnel.

\section{Literature Review}

'Alexia Malewaik' in his technical article presented the types of audits, the methods of conducting an audit. The audit not only tests the accuracy of invoices and other charges incurred against the construction project, but may include a review of processes used in project management and project cost/ schedule controls, and a comparison of those processes to industry best practices. Thus, the audit function is an essential project control tool.

D.Sailendra stated safety audit as a vital tool in the hands of top management to ascertain current status of safety scenario, for improving safety performance and for successful implementation of safety programs in construction organizations in India.

Dr. P.Sivaprakash stated safety audit system as an important tool for identifying and assessing the status of existing occupational safety and health management system in an industry. It was carried out by qualified occupational safety and health management professionals or safety auditors. A report of the safety audit was prepared by the audit team bringing out the strength and weaknesses of the occupational safety and health system of the industry along with the recommendations for improvements.

\section{Methodology}

This research involves the study of the safety audit management system in Kuwait. Literature review was done to identify the objectives of the safety audit management system, the relevance of using the safety audit management system on construction sites, to familiarize with the various 


\section{International Journal of Science and Research (IJSR) \\ ISSN (Online): 2319-7064}

Index Copernicus Value (2013): 6.14 | Impact Factor (2015): 6.391

elements used for the audit and to incorporate the most relevant and major elements into the audit that was prepared. Further this audit was implemented in SSH International, Kuwait. The audit score was given to the consultancy. Based on the audit findings, corrective actions and improvement measures were given. Further, the impact the safety audit had on the consultancy was studied.

\section{Steps Involved}

- To study the literature available in the form of books, journals and certified audit checklists to get a proper understanding of safety audits.

- Identification of the elements of the audit through literatures and certified checklists.

- Preparation of the safety audit on Microsoft Excel.

- Conducting the audit in the construction site.

- Suggesting the corrective actions and improvement methods.

- Impact of the safety audit was studied.

\section{Research Methodology}

\section{Identification of the safety audit elements}

Different certified consultancies and companies have incorporated different safety elements into their checklists. After the review and study of various literatures and certified checklists, 19 major safety elements that could affect the health and safety of the construction workers at the construction site have been shortlisted. The most important ones are presented in Table 1. The audit is prepared on Microsoft Excel.

Table 1

\begin{tabular}{|c|c|}
\hline l. No & $\begin{array}{c}\text { Safety Audit Elements (Factors Causing Accidents in the } \\
\text { Construction Site) }\end{array}$ \\
\hline 1. & HSE Resources of Contractor \\
\hline 2. & PPE \\
\hline 3. & Fall Protection \\
\hline 4. & Excavations \\
\hline 5. & Scaffolds \& ladders / Temporary works \& platforms \\
\hline 6. & Hoisting and Lifting Equipment / MEWP \\
\hline 7. & Vehicles and mobile equipment/ Plants \\
\hline 8. & Tools and Equipment \\
\hline 9. & Fire protection and hot works \\
\hline 10. & Permits to work \\
\hline 11. & Confined spaces \\
\hline 12. & Electrical works \\
\hline 13. & Environmental \\
\hline 14. & Traffic Safety Management \\
\hline 15. & First Aid \\
\hline 16. & Occupational Health \\
\hline 17. & House-keeping site conditions \\
\hline 18. & Amenities/ Sanitation \\
\hline 19. & \\
\hline
\end{tabular}

\section{Data Collection}

For collection of data for the safety audit, the audit was implemented in SSH International, Kuwait. Physical checks/inspections were done, safety engineers, safety officers and others involved in addressing the safety at the workplace were contacted. Safety records, safety logs, safety registers, minutes of safety meetings, etc. were assessed.

\section{Data Analysis Method}

The above given 19 checks are present in the audit. The checks are prepared in such a way that each check contains further parts. Each element is to be rated on $100 \%$ as $0 \%$, $50 \%, 75 \%$ and $100 \%$ respectively.

$0 \%$ - evidence of no compliance and /or no implementation $50 \%$ - evidence of partial compliance and /or no implementation.

$75 \%$ - evidence of full compliance with only minor exceptions in implementation.

$100 \%$ - evidence of full compliance and full implementation.

The possible score would be out of 50 . The percentage on 100 would then be converted to the actual score. The actual score for each main check (audit element) will then be found by summing up all the actual scores of the sub-checks.

In the executive summary, the actual and possible score for each of the main checks are found.

Percentage of compliance

$$
(\text { Score })=\frac{\Sigma \text { Actual Score }}{\text { Possible Score }} \mathrm{X} 100
$$

The percentage score for each Audit element was found. These audit elements were then ranked according to their criticality.

\section{Analysis and Results}

Data collected from site using the audit were analysed using the MS excel software. The percentage score for the factors under each audit element is shown in the table. This percentage score explains the criticality of the elements; it can also show the extent to which these elements would affect the safety of the workers in the construction site. The percentage score given to the consultancy was $79 \%$

Table 2

\begin{tabular}{|c|c|c|c|}
\hline Sl. No & $\begin{array}{c}\text { Safety audit elements (factors causing } \\
\text { accidents in the construction site })\end{array}$ & Percent & Rank \\
\hline 1. & HSE Resources of Contractor & 81 & 7 \\
\hline 2. & PPE & 75 & 2 \\
\hline 3. & Fall Protection & 86 & 9 \\
\hline 4. & Excavations & 75 & 2 \\
\hline 5. & $\begin{array}{c}\text { Scaffolds \& ladders / Temporary works \& } \\
\text { platforms }\end{array}$ & 78 & 4 \\
\hline 6. & Hoisting and Lifting Equipment / MEWP & 84 & 8 \\
\hline 7. & Vehicles and mobile equipment/ Plants & 77 & 3 \\
\hline 8. & Tools and Equipment & 75 & 2 \\
\hline 9. & Fire protection and hot works & 75 & 2 \\
\hline 10. & Permits to work & 75 & 2 \\
\hline 11. & Confined spaces & 79 & 5 \\
\hline 12. & Electrical works & 71 & 1 \\
\hline 13. & Legal requirements/ HSE inspections & 90 & 10 \\
\hline 14. & Environmental & 81 & 7 \\
\hline 15. & Traffic Safety Management & 84 & 8 \\
\hline 16. & First Aid & 80 & 6 \\
\hline 17. & Occupational Health & 75 & 2 \\
\hline 18. & House-keeping site conditions & 80 & 6 \\
\hline 19. & Amenities/ Sanitation & 71 & 1 \\
\hline & & & \\
\hline
\end{tabular}




\section{International Journal of Science and Research (IJSR) \\ ISSN (Online): 2319-7064}

Index Copernicus Value (2013): 6.14 | Impact Factor (2015): 6.391

The six most important factors that could affect the health and safety of the construction personnel at the construction worksite

19 audit elements were selected for this study. Out of these 19 elements, 6 elements were ranked as the primary and secondary causes of accidents. The improper usage of the following 6 elements could affect thehealth and the safety of the construction personnel at the construction site. The six most important elements were the following: Amenities/Sanitation, Electrical Works, Excavations, Tools and equipment, Fire protection and hot works, and Personal Protective Equipment's (PPE's) and these have been described below.

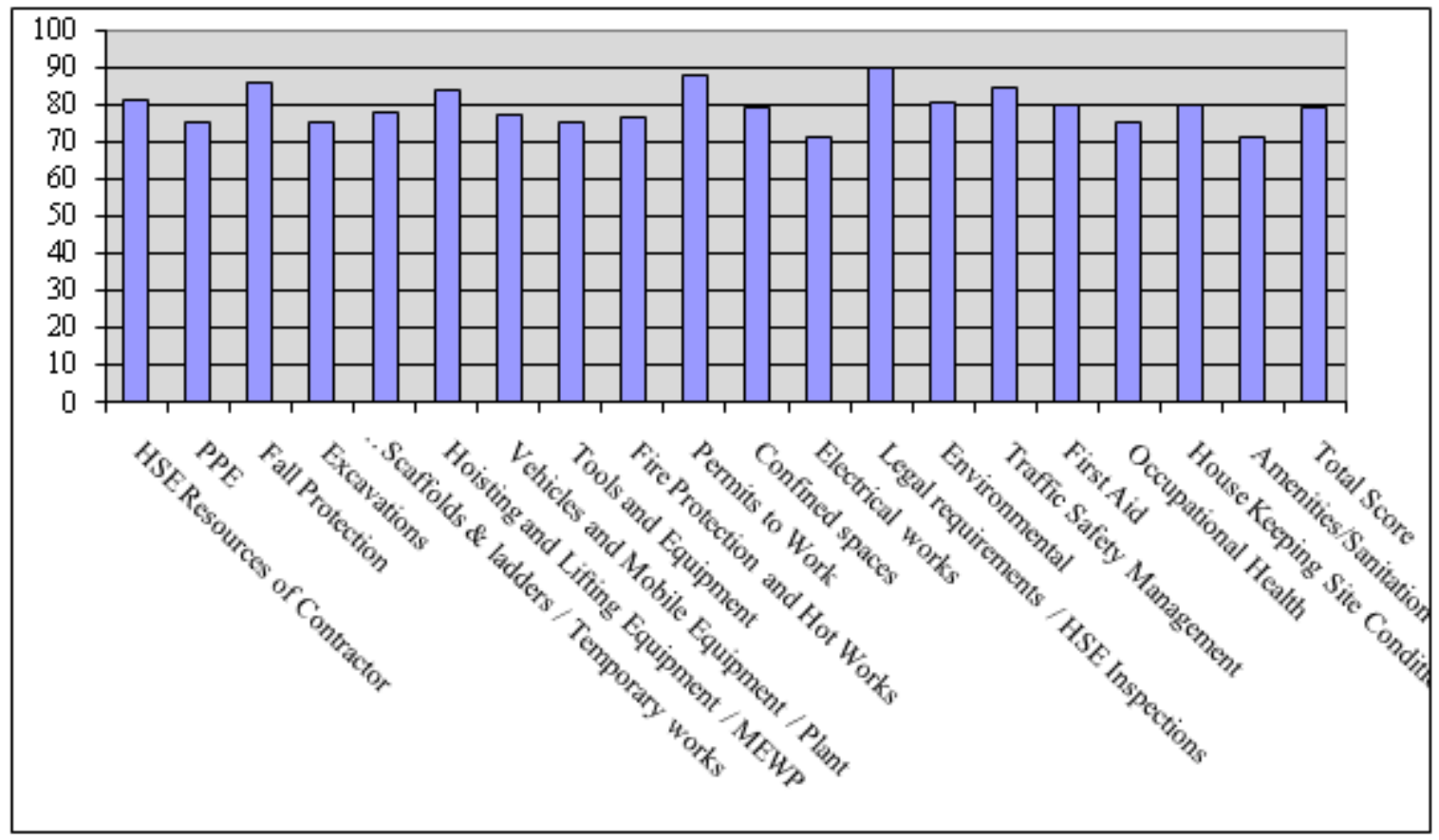

\section{1) Amenities and Sanitation}

From the graph it is clear that amenities/sanitation has a score of $71 \%$ and it has been ranked 1 . Therefore, it can be a major problem that could cause accidents at the construction site. If proper amenities/ sanitation is not provided to the workers, this can directly affect the health of the workers which can be a major cause affecting the health of the construction personnel.

2) Electrical Works

Electrical works are most often not treated with the respect it deserves. From the graph above its seen that it has a score of $71 \%$ and it has also been ranked 1 . Therefore, it could also be a cause of accidents at the construction site. Shock related burns can cause accidents. Short circuits can also cause accidents.

3) Excavations

Excavations are vital for the construction projects. It is often required to dig a trench for typical installations. Excavations are recognized as dangerous working areas. From the graph it has been seen that an excavation has a score of $75 \%$ and it is ranked as one among the primary causes for accidents.

4) Tools and Equipments

Heavy machine equipment used on construction sites can fail or be dangerous. From the graph the score of this particular audit element has been found to be $75 \%$ and it has been ranked as a secondary cause to an accident in the construction site.

5) Fire Protection and Hot Works

Fire is a real threat on any construction site, and usually ignition is from a simple cause such as careless smoking, no housekeeping, and sloppy maintenance on electrical tools, portable heating, and lack of adequate fire watch or faulty wiring. From the graph, this audit element has a score of $75 \%$ and it has also been ranked as the secondary cause to an accident in the construction site.

6) PPE

Personal Protective Equipment's (PPEs) are essential in a construction site. The lack of PPEs used in the construction sites can lead to tremendous amounts of accidents. From the graph, PPE has a score of $75 \%$ and it has also been ranked as the secondary cause to an accident in a construction site.

\section{Conclusions and Suggestions}

The main objective of the thesis was to determine the safety audit elements that could affect the health and safety of the construction personnel, to know their causes, and to identify ways of preventing or solving these problems. 19 major factors contributing to the accidents at the construction worksite were selected for the study. For collecting the data for this project, a safety audit was conducted in the International Consultancy, SSH International, Kuwait. MS Excel Software was used for analysis of the data. From the analysis and results all the 19 factors were ranked according to the criticality by which it would cause accidents. From the study of the Safety Audit Management System in this consultancy, the most important factors that could affect the health and safety of the construction personnel if not given due importance were the following: Amenities/Sanitation, Electrical Works, Excavations, Tools and equipment, Fire 


\section{International Journal of Science and Research (IJSR) \\ ISSN (Online): 2319-7064}

Index Copernicus Value (2013): 6.14 | Impact Factor (2015): 6.391

protection and Hot works, and Personal Protective Equipment's(PPE's).

Amenities/Sanitation most often is not given much importance in the construction worksite. It must be noted that this factor could cause a lot of negative impact on the health of the Construction personnel without whom nothing is possible in the construction worksite. Some of the corrective measures suggested was to provide clean drinking water, in the containers that are capped properly. Drinking water containers must be constructed of materials that maintain the water quality. Clean spaces like Cafeterias must be provided for the workers. Waste must be disposed-off properly.

Electrical works was the next major factor that could cause accident and this is also most often not treated with the respect it deserves. Shock related burns, short circuits, etc. are some of the accidents it could cause. This factor is important as it can directly affect the life of the construction workers. The important measures provided was that the safety and health programs must address electrical incidents and the variety of ways electricity becomes a hazard.

Excavation was the next major factor that would cause an accident. It's often required to dig trenches for a typical installation. Excavations are recognised as dangerous working areas. Some of the corrective measures suggested were: the waste earth and construction materials must not be stored within $2 \mathrm{~m}$ of the edge of any excavation. Ladder access must be available every $12 \mathrm{~m}$ for access and egress. Excavations must be clearly marked and barricaded. Heavy equipment must be kept at a minimum of $2 \mathrm{~m}$ from the edge of excavation depending on soil type/ compaction factor and angle of repose.

Tools and equipment is the next major factor that would cause a construction accident. Heavy machine equipment used on construction site can fail or be dangerous. Tools and equipment according to the study has been found to be the major source of cause of an accident at the construction worksite. The corrective measure suggested was that broken ladders or hammers, axes and similar equipment's must be replaced immediately. Suitable and sufficient tools to be used for the task performed. Appropriate safety glasses, face shields, etc. must be used while using hand tools or equipment's which might produce flying materials or be subject to breakage. Explosive actuated tools must have prior written approach of the Contractors Safety Manager before delivery. Only trained operators shall be operating such tools to ensure safe and proper usage.

The next major cause of accidents was found to be Fire Protection and Hot works. Fire is a real threat on any construction site and ignition is usually from a simple cause such as careless smoking, no housekeeping, sloppy maintenance on electrical tools, portable heating, lack of adequate fire watch or faulty wiring, etc. Some of the corrective measures suggested was that the flammable materials and chemicals be stored according to the manufacturer's instructions/MSDS data and work environment, fire extinguishers to be located in accordance with emergency plan, inspected and tagged for the current month, flashback arrestors installed on the cylinders, compressed gas cylinders need to be stored, transported and maintained in accordance with the manufacturers recommendations. Regulators must be taken in place and it must not be damaged.

Last but not the least major cause of accident at the construction site was found to be PPEs. Lack of PPEs used in the construction sites can lead to tremendous amounts of accidents. Some of the corrective measures suggested were more implementation of hard hats, provision of comfortable scratch free goggles, hand protection that satisfy standards for each work need to be provided. The ill-effects that could be caused because of the lack of usage of PPEs must be taught to the workers.

Finally, to conclude, a safety audit is the most effective method by which the factors that could affect the health and safety at the construction worksite could be addressed. The actual worksite conditions could be taken into account through the audit and based on the happenings at the worksite, the suggestive measures could be given.

\section{References}

[1] Alexia Nalewaik, 'Construction Audit- an essential audit control function', 'International Journal of Engineering Trends and Applications (IJETA)' Volume 4 Issue 3, May-June 2014

[2] K.Stephens, M.T. Roszak (2010), 'A study of the role and benefits of third party auditing in quality Management System', 'Journal of Achievements in Materials and Manufacturing Engineering', Volume 43 Issue 2, Dec2010

[3] D.Sailendra, Awadhesh Shah, 'Study of Internal and External Safety Audit by Gap Analysis approach in Indian Construction Organisations' , 'International Journal of Engineering Trends and Applications (IJETA)', - Volume 2 Issue 3, May-June 2015

[4] M.N. Vinodkumar, M. Bhasi, 'A study on the impact of management system certification on safety management', ELSEVIER:Nov2010

[5] John Smallwood, 'Optimising the elements of a construction health and safety(H\&S) program and audit system', ELSEVIER- Creative Construction Conference- 2015

[6] Marcelo Fabiano Costella, Tarcisio Abreu Saurin, Lia Buarque de Macedo Guimarães , 'A method for assessing health and safety management systems from the resilience engineering perspective', ELSEVIERSafety Science 47(2009), 1056-1067

[7] G.Grole, C. Kù̀ nzler, 'Diagnosis of safety culture in safety management audits', Safety Science 34 (2000) $131-150$

[8] Wil van der Aalst, Kees van Hee, Jan Martijn van der Werf , Akhil Kumar, 'Conceptual Model for online auditing', Decision Support Systems 50 (2011) 636-647

[9] Zubaidah Ismail, Samad Doostdar, Zakaria Harun, 'Factors influencing the implementation of a safety management system for construction sites', Safety Science 50 (2012) 418-423

[10] Rebecca Mitchell, Rena Friswell, Lori Mooren, ' Initial development of a practical safety audit tool to assess 


\section{International Journal of Science and Research (IJSR) \\ ISSN (Online): 2319-7064}

Index Copernicus Value (2013): 6.14 | Impact Factor (2015): 6.391

fleet safety management practices', Accident Analysis and Prevention 47 (2012) 102- 118

[11]Dr.

P.Sivaprakash,

Dr.R.K.Elangovan, L.M.Karthikeyan, Sebastian joseph, 'A Study on Safety Audit System in Indian Engineering Industries', Life Science Journal 2013;10(9s)

[12] John Smallwood, 'Optimising the elements of a construction health and safety $(\mathrm{H} \& \mathrm{~S})$ programme and audit system', Procedia Engineering 123 ( 2015 ) 528 537- Creative Construction Conference 2015 (CCC2015)

[13] Yumei Wanga, Man Lib, 'The Role of Internal Audit in Engineering Project Risk Management', Procedia Engineering 24 (2011) 689 - 694- 2011 International Conference on Advances in Engineering

[14]Dr. Alexia Nalewaika, Professor Anthony Mills, 'Project Performance Audit: Enhanced Protocols for Triple Bottom Line Results', Procedia - Social and Behavioral Sciences 194 ( 2015 ) 134 - 145- 28th IPMA World Congress, IPMA 2014, 29 September - 1 October 2014, Rotterdam, The Netherlands

[15] Safety Management System Audit (OTN management system audit)

[16] Veritas Consulting- construction site health and safety audit

[17] Environmental and Occupational Health and Safety Unit

[18] ISO14001 Environmental system

[19] Checklist for an Audit of Safety Management SystemOGP Publications

\section{Author Profile}

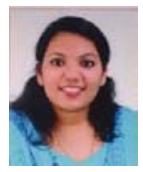

Sophiya Sunny Pulickal received her B'tech degree in Civil Engineering from (Mar Athanasius College of Engineering, Kothamangalam) M.G. University. At present pursuing her Masters in Engineering in RVS, Technical Campus, Coimbatore affiliated to Anna University. She published a paper on Study of Fibre reinforced bituminous concrete in the International Journal IJERD in June 2014. Her specialisation area is Construction Engineering and Management.

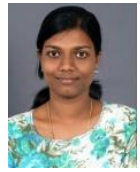

Blessy B. completed her Bachelors in Civil Engineering from Ranganathan Engineering College, Coimbatore and Masters in Engineering from RVS Technical Campus, Coimbatore. Her interests are Building technology and Construction Management.

Pratap Reddy completed his Bachelors in Mechanical Engineering from Kolkata University and Masters in Engineering from Karnataka Open University. Presently, working as the Safety Engineer at SSH International, Kuwait. 